\title{
Additional benefit in CVD risk indices derived from the consumption of fortified milk when combined with a lifestyle intervention
}

\author{
Maria Petrogianni ${ }^{1}$, Evangelia Grammatikaki ${ }^{1}$, Nikolaos Kalogeropoulos $^{1}$, \\ Anna Peristeraki ${ }^{1}$, George Moschonis ${ }^{1}$, Christos Pitsavos ${ }^{2}$, Smaragdi Antonopoulou ${ }^{1}$ \\ and Yannis Manios ${ }^{1, *}$ \\ 'Department of Nutrition and Dietetics, Harokopio University, 70 Elefteriou Venizelou Street, 17671 Athens, \\ Greece: ${ }^{2}$ First Cardiology Clinic, School of Medicine, University of Athens, Athens, Greece
}

Submitted 19 March 2012: Final revision received 29 September 2012: Accepted 29 0ctober 2012: First published online 18 December 2012

\begin{abstract}
Objective: The current study aimed to evaluate the effect of fortified milk combined with a lifestyle and counselling programme on several CVD risk factors after a 3-month dietary intervention.

Design: Hypercholesterolaemic adults were randomized to a group supplemented with low-fat milk that was enriched with phytosterols, $\alpha$-linolenic and linoleic fatty acids, vitamins and antioxidants (enriched milk group, EMG: $n$ 40), a placebo milk group (PMG: $n$ 36) or a control group (CG: $n$ 25). The EMG and PMG consumed respectively $500 \mathrm{ml}$ of enriched milk or placebo milk daily and attended biweekly counselling sessions over a 3-month period.

Setting: Harokopio University, Athens, Greece.

Subjects: A sample of 101 hypercholesterolemic adults aged 40-60 years.

Results: Regarding lifestyle changes, total and saturated fat intakes decreased significantly in both intervention groups compared with the CG $(P<0.005)$. Furthermore, total steps were increased $(P=0.029)$ and BMI was decreased $(P=0 \cdot 017)$ significantly in both intervention groups compared with the CG. Regarding biochemical indices, EPA content in erythrocyte membranes increased $(P<0 \cdot 001)$ while serum C-reactive protein decreased $(P=0 \cdot 003)$ significantly in both intervention groups compared with the CG. Finally, significant increases in plasma folic acid and vitamin $\mathrm{B}_{12}$ levels and a significant decrease in homocysteine levels were observed in the EMG compared with the PMG and CG (all $P<0 \cdot 001$ ). A favourable change in LDL cholesterol:HDL cholesterol was also observed in the EMG and tended to be significant compared with the PMG and CG $(P=0 \cdot 066)$. Conclusions: The present study showed that consumption of fortified milk accompanied with lifestyle counselling induces extra benefits in terms of LDL cholesterol:HDL cholesterol and serum homocysteine levels.
\end{abstract}

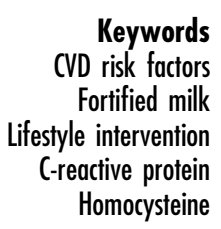

CVD is a major cause of morbidity and mortality worldwide $^{(1)}$. There is now a plethora of evidence from epidemiological and clinical studies suggesting that modifications of dietary fat composition alter the risk of CVD, while total cholesterol (TC) and LDL cholesterol (LDL-C) concentrations are the most significant modifiable risk factors contributing to CVD mortality. A meta-analysis of forty-one published studies in hypercholesterolaemic patients and people with normal lipid levels concluded that an intake of plant sterols or stanols of $2-2.5 \mathrm{~g} / \mathrm{d}$ reduces LDL-C concentration by $\sim 10 \%{ }^{(2)}$. Furthermore, PUFA - especially long-chain $n-3$ PUFA which are found mainly in fish and seafood - have been shown to exhibit several beneficial effects with regard to
CVD risk (i.e. reduction of serum TAG, lipoproteins, homocysteine, C-reactive protein (CRP), cytokines and blood pressure levels $)^{(3-7)}$. Antioxidants such as vitamins E and $\mathrm{C}$ and $\mathrm{Se}$ have been shown to play a protective role against PUFA oxidation ${ }^{(8,9)}$. Supplementation with vitamin $\mathrm{E}$ has been shown to double the lag time to LDL oxidation $^{(10)}$, while vitamin $\mathrm{C}$ is believed to regenerate vitamin $\mathrm{E}$ from its oxidized state back to its activated state $^{(11)}$. Furthermore, Se is an important component of the antioxidant enzyme glutathione peroxidase that protects cells from the adverse effects of free radicals and lipid peroxides ${ }^{(11)}$. Other important nutrients that have been associated with a reduction of CVD risk are folic acid and vitamins $\mathrm{B}_{6}$ and $\mathrm{B}_{12}{ }^{(6,12,13)}$. These nutrients when 
provided in combination with $n-3$ PUFA, usually as components of fortified food products, have consistently shown a reduction in plasma homocysteine levels, an independent CVD risk factor ${ }^{(6,14,15)}$, via its metabolic conversion to cystathionine or methionine ${ }^{(16)}$. Finally, it is well documented that regular dietary and/or supplementary intake of $\mathrm{Ca}$ and $\mathrm{Mg}$ has a significant blood-pressurelowering effect ${ }^{(17-19)}$.

Until now, no study has examined the combined effect of all these nutrients that seem to reduce CVD risk when combined in a single food product. Furthermore, in most intervention studies providing fortified products, study participants received no further motivation to increase their compliance to the intervention scheme. The aim of the current study was to examine the effectiveness of a holistic approach combining the consumption of milk enriched with phytosterols, $\alpha$-linolenic and linoleic fatty acids, vitamins and antioxidants, as well as regular lifestyle and nutrition counselling sessions, in reducing CVD risk factors compared with a group that received plain milk and lifestyle and nutrition counselling and a control group.

\section{Experimental methods}

\section{Sampling}

Participants were recruited via advertisement; a total of 340 men and women volunteered to participate. Inclusion criteria were age 40-60 years, BMI $<35 \cdot 0 \mathrm{~kg} / \mathrm{m}^{2}$, TC $>200$ but $<310 \mathrm{mg} / \mathrm{dl}$ and no use of lipid-lowering medications, as well as absence of metabolic disorders other than hypercholesterolaemia (i.e. diabetes, thyroid, renal and hepatic disease). One hundred and fifteen volunteers were considered eligible and were invited to participate in the study. The experimental protocol was approved by the Ethics Committee of Harokopio University, Athens, and all participants provided signed informed consent.

\section{Experimental protocol}

Participants were equally randomized into two intervention arms and one control arm, each lasting for 3 months: (i) a group supplemented with a low-fat milk enriched with phytosterols, $\alpha$-linolenic and linoleic fatty acids, vitamins and antioxidants (enriched milk group; EMG); (ii) a placebo milk group (PMG); and (iii) a control group (CG) receiving no product. The allocation into the two intervention arms was performed in a double-blind fashion. EMG and PMG participants were instructed to consume two portions ( $250 \mathrm{ml}$ each) of milk daily. The placebo product was plain low-fat milk (1·8\%). The tested product was the same low-fat milk enriched (per $100 \mathrm{~g}$ ) with $0.5 \mathrm{~g}$ of plant sterols, $0.43 \mathrm{~g}$ of linoleic acid, $0.04 \mathrm{~g}$ of $\alpha$-linolenic acid, $40 \mathrm{mg}$ of vitamin C, $7 \cdot 88 \mathrm{mg}$ of vitamin E, $111 \mu \mathrm{g}$ of vitamin $\mathrm{A}, 2.5 \mathrm{mg}$ of vitamin $\mathrm{B}_{6}, 2.5 \mu \mathrm{g}$ of vitamin $\mathrm{B}_{12}, 100 \mu \mathrm{g}$ of folic acid, $22 \mathrm{mg}$ of $\mathrm{Mg}$ and $25 \mu \mathrm{g}$ of Se. The milk consumed by both groups contained (per $100 \mathrm{~g}$ ) $3.5 \mathrm{~g}$ of protein, $4.6 \mathrm{~g}$ of carbohydrate and $1.8 \mathrm{~g}$ of fat for a total energy of $205 \mathrm{~kJ}$ ( $49 \mathrm{kcal}$ ). The study products were all packaged in $1000 \mathrm{ml}$ bottles (Friesland Campina Hellas, Athens, Greece).

Participants in the EMG and PMG attended seven dietary and lifestyle counselling hourly sessions, held biweekly in order to ensure compliance. The sessions were based on the Health Belief Model and Social Cognitive Theory ${ }^{(20,21)}$ and aimed at increasing awareness regarding health issues, especially those related to CVD, and motivate participants to set targets and change certain dietary and physical activity habits for improving cardiovascular risk and health status in general. Gradually, the sessions became more interactive and emphasis was placed on increasing self-efficacy in making changes to improve everyday habits. Some of the topics covered during these sessions included: reducing total and saturated fat intakes (replacing full-fat dairy products with the provided and other low-fat products), increasing fruit and vegetable intake, increasing fish consumption (especially fatty ones) and increasing physical activity. Participants in the CG only received a pamphlet on healthy lifestyle, including information on diet and physical activity; they did not attend any dietary and lifestyle counselling sessions.

During the week before and after the intervention, all participants came to the laboratory for anthropometric, nutritional and physical activity evaluation and blood sample collection.

\section{Antbropometric assessment and blood pressure}

Body weight was measured to the nearest $0 \cdot 1 \mathrm{~kg}$ on a digital scale (Seca Alpha model 770, Hamburg, Germany) and standing height was recorded to the nearest $0.5 \mathrm{~cm}$ with a commercial stadiometer (Leicester Height Measure; CMS Instruments, Oxford, UK), while the participants wore light clothing and no shoes. BMI was calculated by dividing weight by the square of height $\left(\mathrm{kg} / \mathrm{m}^{2}\right)$. Blood pressure was measured in the right arm, with the participant seated and quiet after a $5 \mathrm{~min}$ rest, using a validated automated sphygmomanometer (Omron M6 Blood Pressure Monitor, Tokyo, Japan) ${ }^{(22)}$.

\section{Nutritional assessment}

Three $24 \mathrm{~h}$ recalls (two consecutive weekdays and one weekend day) were obtained and data were analysed with Nutritionist V diet analysis software version $2 \cdot 1$ (First Databank, San Bruno, CA, USA), which was extensively amended to include data on Greek foods and recipes from the Greek food composition tables and on commercial food items widely consumed in Greece obtained by chemical analysis ${ }^{(23,24)}$

\section{Physical activity assessment}

Physical activity was assessed by recording of one week's steps with the use of a pedometer (Yamax DigiWalker SW-200, Tokyo, Japan) as described by Strycker et al. ${ }^{(25)}$. 


\section{Biochemical analyses}

Fasting HDL cholesterol (HDL-C), TAG and C-reactive protein (CRP) were determined by photometric methods. All analyses were carried out by an automated centrifugal analyser with commercially available assays (Roche/Hitachi modular system, P800 module, Japan). LDL-C was calculated with the Friedewald equation, and VLDL cholesterol was calculated by subtraction from TC. Total fasting plasma homocysteine concentration was measured by immunoturbidometric method by an automated centrifugal analyser with commercially available assays (Abbott AxSYM, Abbott Park, IL, USA). Plasma folic acid and vitamin $\mathrm{B}_{12}$ concentrations were measured by electrochemiluminescence (Roche E170).

For the determination of fatty acids in erythrocyte membranes, venous blood samples were collected into EDTA-containing Vacutainer tubes and centrifuged immediately after collection at $4000 \mathrm{rpm}$ for $10 \mathrm{~min}$ at $4^{\circ} \mathrm{C}$ (Universal 32R centrifuge; Hettich Laboratories, Tuttlingen, Germany). Supernatant plasma was then removed. Erythrocytes were washed and transferred into a freezer at $-80^{\circ} \mathrm{C}$ for long-term storage until analysed. For fatty acid analysis, $300 \mu \mathrm{l}$ of deep-frozen packed erythrocytes were thawed, vortexed, transferred to pre-weighed $10 \mathrm{ml}$ Teflon-coated screw-capped tubes and precisely weighed. The erythrocyte membrane lipids were extracted and purified with chloroform-isopropanol as described by Rose and Oklander ${ }^{(26)}$ and their fatty acid profiles were determined by GC of their methyl esters (FAME), which were prepared by the acetyl chloride methylation procedure described by Lepage and Roy ${ }^{(27)}$. For the measurement of FAME, an Agilent HP series GC 6890 (Avondale, PA, USA) equipped with a flame ionization detector, split-splitless injector and an HP 6890 autosampler were employed. An aliquot $(1 \mu \mathrm{l})$ of plasma FAME was injected into the gas chromatograph at a split ratio of $1: 10$. Separation of FAME was achieved on an SGE BPX70 capillary column $(60 \mathrm{~m}$ long, $0.25 \mathrm{~mm}$ internal diameter), coated with a $0 \cdot 25-\mathrm{mm}$ thick film of cyanopropyl silicone. He gas was used as the carrier at a flow rate of $0 \cdot 8 \mathrm{ml} / \mathrm{min}$; the injector and detector were held at $230^{\circ} \mathrm{C}$ and $290^{\circ} \mathrm{C}$, respectively, and the oven temperature programme was from $130^{\circ} \mathrm{C}$ to $250^{\circ} \mathrm{C}$ at a rate of $3^{\circ} \mathrm{C} / \mathrm{min}$. FAME peak identification was accomplished by means of a standard mixture of thirty-seven FAME purchased from Sigma (St Louis, MO, USA). The mixed FAME standard was injected periodically to record slight changes in retention times, while it furthermore served for the calculation of fatty acid response factors that were applied to the areas derived from the chromatographic traces. Quantification of fatty acids was accomplished by employing methyl nonanoate as internal standard and constructing reference curves by means of several dilutions of the FAME polystandard. For this purpose, $100 \mu$ l of the internal standard solution (methyl nonanoate, $1 \mathrm{mg} / \mathrm{ml}$ ) was added both in standards and samples prior to analysis. Blood samples for each individual were processed in parallel to ensure that minor variations in sample handling were minimized.

\section{Statistical analysis}

All data are reported as the mean and standard deviation or as the mean change and 95\% confidence interval over baseline. Variables were examined for normality of distribution according to the Kolmogorov-Smirnov test. Baseline characteristics of the groups were compared with the use of one-way ANOVA for continuous variables and by the $\chi^{2}$ test for categorical variables. For educational level, the non-parametric Kruskal-Wallis test was used. Data were analysed by using ANOVA for repeated measurements with time as a within-subject factor (baseline $v$. follow-up) and group as a between-subject factor (CG $v$. PMG $v$. EMG). When significant group $\times$ time interactions emerged, further analysis was carried out to evaluate the significance of changes over time within each group, by using Student's paired $t$ test, and the significance of differences among groups before and after the intervention, by using one-way ANOVA. When necessary, ANCOVA was performed to adjust for potential confounders. Statistical analysis was carried out with SPSS statistical software package version $13 \cdot 0$. A two-tailed $P \leq 0.05$ was considered statistically significant. The covariate that was used in all statistical analysis was education.

\section{Results}

Seven of the 115 participants initially assigned to participate in the study could not be re-examined at the 3-month follow-up and analysis of the fatty acid content in erythrocyte membranes could not be performed in seven of the remaining participants, providing a total of 101 participants with full data from both examinations. Consequently the number of participants in each group with full baseline and follow-up data was forty for the EMG, thirty-six for the PMG and twenty-five for the CG. The mean age of the participants was $48 \cdot 7$ (SD $8 \cdot 6$ ) years and $46.5 \%$ of them were women. No significant differences were observed at baseline regarding the mean values of anthropometric and body composition indices as well as the percentage of participants smoking or being overweight or obese (Table 1). Significant differences were observed for educational status (lower years of education in the CG, $P=0 \cdot 016$ ) and therefore all further analyses were performed using this variable as a covariate.

According to the data presented in Table 2, the changes observed between baseline and follow-up for energy intake and percentage of energy intake derived from carbohydrate, protein and PUFA did not differ significantly among the study groups. However, a significant decrease with respect to percentage of energy intake derived from total fat was found for the EMG and PMG compared with the CG, who increased their intake 
Table 1 Baseline descriptive characteristics according to study group: hypercholesterolaemic adults ( $n$ 101) aged 40-60 years, Athens, Greece

\begin{tabular}{|c|c|c|c|c|c|c|c|}
\hline & \multicolumn{2}{|c|}{ EMG $(n 40)$} & \multicolumn{2}{|c|}{ PMG (n 36) } & \multicolumn{2}{|c|}{ CG $(n 25)$} & \multirow[b]{2}{*}{$P$ value* } \\
\hline & Mean & SD & Mean & SD & Mean & SD & \\
\hline Age (years) & $49 \cdot 5$ & $9 \cdot 2$ & $47 \cdot 2$ & $8 \cdot 2$ & $49 \cdot 5$ & $8 \cdot 3$ & $0 \cdot 451$ \\
\hline Educational level (years) & $13 \cdot 9$ & $3 \cdot 2$ & $13 \cdot 9$ & $3 \cdot 3$ & $11 \cdot 6$ & $4 \cdot 3$ & $0 \cdot 016 t$ \\
\hline Weight $(\mathrm{kg})$ & $79 \cdot 7$ & $12 \cdot 7$ & $79 \cdot 9$ & $14 \cdot 9$ & $75 \cdot 4$ & $14 \cdot 7$ & 0.395 \\
\hline Height $(\mathrm{cm})$ & $167 \cdot 4$ & $7 \cdot 8$ & $167 \cdot 6$ & $10 \cdot 9$ & $166 \cdot 4$ & $8 \cdot 6$ & $0 \cdot 868$ \\
\hline BMI $\left(\mathrm{kg} / \mathrm{m}^{2}\right)$ & $28 \cdot 3$ & $3 \cdot 4$ & $28 \cdot 5$ & $4 \cdot 3$ & $27 \cdot 0$ & $3 \cdot 6$ & 0.295 \\
\hline \multirow[t]{2}{*}{ Fat mass ( $\%$ body weight) } & $40 \cdot 0$ & $5 \cdot 8$ & $38 \cdot 3$ & $7 \cdot 0$ & $37 \cdot 9$ & $5 \cdot 3$ & $0 \cdot 327$ \\
\hline & $n$ & $\%$ & $n$ & $\%$ & $n$ & $\%$ & \\
\hline Females & 20 & $50 \cdot 0$ & 14 & 38.9 & 13 & $52 \cdot 0$ & 0.512 \\
\hline Smokers & 16 & $40 \cdot 5$ & 18 & $51 \cdot 4$ & 13 & $52 \cdot 0$ & 0.566 \\
\hline Weight status & & & & & & & $0 \cdot 391$ \\
\hline Normal weight & 5 & $12 \cdot 5$ & 7 & $19 \cdot 4$ & 8 & $32 \cdot 0$ & \\
\hline Overweight & 23 & $57 \cdot 5$ & 21 & $58 \cdot 3$ & 11 & $44 \cdot 0$ & \\
\hline Obese & 12 & $30 \cdot 0$ & 8 & $22 \cdot 2$ & 6 & $24 \cdot 0$ & \\
\hline
\end{tabular}

EMG, enriched milk group; PMG, placebo milk group; CG, control group.

${ }^{*} P$ values were derived by one-way ANOVA for continuous variables and by the $\chi^{2}$ test for categorical variables. tDerived from the non-parametric Kruskal-Wallis test.

$(P=0 \cdot 037)$. Similar were the findings for percentage of energy intake derived from saturated fat $(P=0 \cdot 042)$. Intake of linoleic acid differed significantly in the EMG compared with the PMG at follow-up $(P=0 \cdot 005)$. Additionally, the intake of $\alpha$-linolenic acid was found to increase only in the EMG, while in the PMG and CG it decreased at follow-up.

After examining the dietary consumption of certain food items, presented in Table 3, the consumption of total and fatty fish was found to increase, albeit insignificantly, in the intervention groups after the end of the intervention, while in the CG it decreased. Significant within-group increases in vegetable consumption were observed in both intervention groups, as well as significant decreases in cheese intake. The consumption of whole grains was significantly increased only in EMG compared with the CG $(P=0 \cdot 025)$. The EMG and $P M G$ increased their milk consumption significantly compared with the CG $(P<0 \cdot 001)$. Changes were also observed at the end of study regarding daily steps and BMI, with the intervention groups exhibiting significantly more favourable values compared with the CG (Table 3 ) for both daily steps $(P=0 \cdot 029)$ and BMI $(P=0 \cdot 017)$.

Table 4 summarises the comparisons between groups with respect to the changes observed during the 3-month intervention period in the concentrations of PUFA in erythrocyte membranes, vitamin $\mathrm{B}_{12}$ and folic acid in plasma. No differences were observed between the three groups for linoleic acid, $\alpha$-linolenic acid, arachidonic acid (AA), DHA and total $n$-3 PUFA, as well as for the ratios $n-3: n-6$ and AA:EPA. The only statistically significant changes were observed for EPA; in both the PMG and EMG, an increase in erythrocyte membrane content of EPA was observed whereas no significant change was observed in the CG $(P<0 \cdot 001)$. Significant within-group changes were observed in all groups for DHA (increased at follow-up $v$. baseline), total $n-3$ fatty acids (increased at follow-up $v$. baseline) and $n-3: n-6$ (decreased at follow-up $v$. baseline). Only in the intervention groups were significant within-group changes in AA:EPA observed (decreased at follow-up $v$. baseline). Regarding plasma vitamin $\mathrm{B}_{12}$ and folic acid, the EMG exhibited significantly increased levels after the 3-month intervention compared with the PMG and CG $(P<0 \cdot 001$ and $P<0 \cdot 001$, respectively).

Table 5 shows the changes in some biochemical indices after the 3-month intervention. Plasma homocysteine levels decreased significantly in the EMG compared with the other groups $(P<0 \cdot 001)$. The EMG had lower LDLC:HDL-C compared with the PMG and CG, the decrement being not significant $(P=0 \cdot 066)$. In both the EMG and PMG, CRP levels decreased significantly compared with the CG $(P=0 \cdot 003)$. In addition, a significant reduction in systolic blood pressure was observed within the intervention groups, while for diastolic blood pressure the reduction was significant only in the PMG.

\section{Discussion}

The findings of the present study were indicative of the effectiveness of a 3-month dietary intervention scheme combining consumption of fortified milk with counselling, aiming to induce favourable changes in dietary and certain CVD risk indices in hypercholesterolaemic adults. Regarding lifestyle changes, both intervention groups (i.e. EMG and PMG) decreased their dietary intakes of total and saturated fat, while they increased their consumption of milk, vegetables, whole grains, total and fatty fish as well as their physical activity levels by $\sim 1000-1500$ steps/d. These favourable lifestyle changes should be mainly attributed to the counselling part of the intervention, since both the EMG and PMG were motivated to decrease their consumption of high-fat foods (i.e. cheese) 
Table 2 Changes in dietary intakes of energy and macronutrients during the 3-month intervention period according to study group: hypercholesterolaemic adults ( $n$ 101) aged 40-60 years, Athens, Greece

\begin{tabular}{|c|c|c|c|c|c|c|c|}
\hline & \multicolumn{2}{|c|}{ Baseline } & \multicolumn{2}{|c|}{ 3-month follow-up } & \multicolumn{2}{|c|}{ 3-month change } & \multirow[b]{2}{*}{$P$ value } \\
\hline & Mean & SD & Mean & SD & Mean & $95 \% \mathrm{Cl}$ & \\
\hline Energy (kJ/d) & & & & & & & 0.968 \\
\hline CG & $6053 \cdot 7$ & $1375 \cdot 2$ & $5596 \cdot 9$ & $1459 \cdot 8$ & $-487 \cdot 2$ & $-1282 \cdot 6,308 \cdot 2$ & \\
\hline PMG & $6343 \cdot 2$ & $1719 \cdot 8$ & $5965 \cdot 6$ & $1958 \cdot 1$ & $-367 \cdot 9$ & $-1015 \cdot 2,279 \cdot 3$ & \\
\hline EMG & $6256 \cdot 4$ & $2185 \cdot 3$ & \multirow{2}{*}{\multicolumn{2}{|c|}{0.878}} & $-370 \cdot 3$ & $-985 \cdot 1,244 \cdot 4$ & \\
\hline$P$ valuet & \multicolumn{2}{|c|}{0.963} & & & & & \\
\hline Carbohydrate (\%E) & & & & & & & 0.083 \\
\hline CG & $43 \cdot 4$ & $8 \cdot 1$ & $44 \cdot 6$ & $9 \cdot 5$ & 0.8 & $-3 \cdot 1,4 \cdot 7$ & \\
\hline PMG & $46 \cdot 9$ & $10 \cdot 4$ & $41 \cdot 8$ & $9 \cdot 0$ & $-4 \cdot 9$ & $-9 \cdot 2,-1 \cdot 8$ & \\
\hline EMG & $44 \cdot 4$ & $10 \cdot 3$ & $42 \cdot 1$ & $7 \cdot 8$ & $-2 \cdot 1$ & $-5 \cdot 1,0.9$ & \\
\hline$P$ valuet & \multicolumn{2}{|c|}{0.462} & \multicolumn{2}{|c|}{0.451} & & & \\
\hline Protein (\%E) & & & & & & & 0.359 \\
\hline CG & $16 \cdot 9$ & $4 \cdot 2$ & $16 \cdot 2$ & $3 \cdot 0$ & -0.5 & $-2 \cdot 3,1 \cdot 2$ & \\
\hline PMG & $17 \cdot 6$ & $3 \cdot 7$ & $18 \cdot 3$ & $4 \cdot 4$ & 0.6 & $-0 \cdot 8,2 \cdot 1$ & \\
\hline EMG & $16 \cdot 7$ & $3 \cdot 6$ & $17 \cdot 6$ & $3 \cdot 2$ & 0.9 & $-0.5,2 \cdot 2$ & \\
\hline$P$ valuet & \multicolumn{2}{|c|}{0.836} & \multicolumn{2}{|c|}{$0 \cdot 126$} & & & \\
\hline Total fat $(\% \mathrm{E}) \ddagger$ & & & & & & & 0.037 \\
\hline CG & $36 \cdot 2$ & $8 \cdot 8$ & $38 \cdot 2$ & $9 \cdot 5$ & $1 \cdot 8$ & $-2 \cdot 3,5 \cdot 9$ & \\
\hline PMG & $40 \cdot 8$ & $9 \cdot 3$ & $38 \cdot 6$ & $6 \cdot 8$ & $-2 \cdot 1$ & $-5 \cdot 5,1 \cdot 2$ & \\
\hline EMG & $43 \cdot 8$ & $8 \cdot 5$ & $39 \cdot 4$ & $6 \cdot 5$ & -3.9 & $-7 \cdot 1,-0 \cdot 7$ & \\
\hline$P$ valuet & \multicolumn{2}{|c|}{0.010} & \multicolumn{2}{|c|}{$0 \cdot 846$} & & & \\
\hline Saturated fat (\%E) & & & & & & & 0.042 \\
\hline CG & $11 \cdot 8$ & $4 \cdot 3$ & $12 \cdot 6$ & $3 \cdot 7$ & 0.4 & $-1 \cdot 3,2 \cdot 2$ & \\
\hline PMG & $13 \cdot 2$ & 4.5 & 11.9 & $2 \cdot 5$ & $-1 \cdot 2$ & $-2 \cdot 7,0 \cdot 2$ & \\
\hline EMG & $12 \cdot 8$ & $3 \cdot 4$ & $11 \cdot 9$ & $4 \cdot 0$ & -0.8 & $-2 \cdot 2,0 \cdot 6$ & \\
\hline$P$ valuet & \multicolumn{2}{|c|}{0.531} & \multicolumn{2}{|c|}{$0 \cdot 846$} & & & \\
\hline PUFA (\%E) & & & & & & & 0.281 \\
\hline CG & $4 \cdot 75$ & $1 \cdot 35$ & $5 \cdot 26$ & $2 \cdot 87$ & 0.55 & $-0.56,1.67$ & \\
\hline PMG & 4.92 & 1.61 & $4 \cdot 55^{b}$ & 1.98 & -0.38 & $-1 \cdot 28,0.53$ & \\
\hline EMG & $5 \cdot 70$ & 1.98 & $6 \cdot 25^{\mathrm{b}}$ & $2 \cdot 11$ & 0.53 & $-0.33,1.40$ & \\
\hline$P$ valuet & \multicolumn{2}{|c|}{0.094} & \multicolumn{2}{|c|}{0.006} & & & \\
\hline Linoleic acid $(\mathrm{g} / \mathrm{d})$ & & & & & & & 0.575 \\
\hline CG & $5 \cdot 96$ & $2 \cdot 97$ & $5 \cdot 53^{a}$ & 1.99 & -0.53 & $-2 \cdot 53,1 \cdot 46$ & \\
\hline PMG & $7 \cdot 16$ & 3.77 & $6 \cdot 17^{\mathrm{b}}$ & 3.49 & -0.97 & $-2.59,0.66$ & \\
\hline EMG & $8 \cdot 10$ & $4 \cdot 87$ & $8 \cdot 27^{a, b}$ & $3 \cdot 70$ & 0.21 & $-1 \cdot 34,1 \cdot 75$ & \\
\hline$P$ valuet & \multicolumn{2}{|c|}{0.272} & \multicolumn{2}{|c|}{0.005} & & & \\
\hline$\alpha$-Linolenic acid $(\mathrm{g} / \mathrm{d})$ & & & & & & & $0 \cdot 213$ \\
\hline CG & 0.62 & 0.23 & $0 \cdot 61$ & 0.23 & -0.03 & $-0.23,0.17$ & \\
\hline PMG & $0 \cdot 79$ & 0.67 & 0.63 & 0.33 & $-0 \cdot 16$ & $-0.32,0.01$ & \\
\hline EMG & 0.69 & 0.29 & 0.73 & 0.23 & 0.05 & $-0.11,0.20$ & \\
\hline$P$ valuet & \multicolumn{2}{|c|}{0.484} & \multicolumn{2}{|c|}{0.194} & & & \\
\hline
\end{tabular}

EMG, enriched milk group ( $n$ 40); PMG, placebo milk group ( $n$ 36); CG, control group ( $n$ 25); \%E, percentage of energy intake.

All analyses were controlled for educational status.

Mean values were significantly different $(P<0 \cdot 05)$ : ${ }^{a} \mathrm{EMG} v$. CG; ${ }^{\mathrm{b}} \mathrm{EMG} v$. PMG.

*Treatment $\times$ time interaction effect.

tBetween-group comparisons at baseline and 3 months (treatment effect).

$\ddagger$ In the case of total fat intake, the analysis was adjusted for baseline values.

by replacing them with low-fat alternatives (i.e. lean meat, fish, fruits, vegetables, etc.) and to increase their daily physical activity level by setting personal goals of walking for at least $20-30 \mathrm{~min} / \mathrm{d}$.

Regarding the favourable dietary changes observed in the current study, these are in line with the findings of intervention studies that used nutrition counselling to reduce CVD risk ${ }^{(28-30)}$. However, regarding changes in physical activity levels, the favourable findings of the present study are in contrast with other similar studies, which confronted difficulties in motivating adults who already had a sedentary lifestyle to become more active ${ }^{(31,32)}$. The use of subjective methods (i.e. questionnaires) to assess changes in physical activity levels during the intervention period could provide an explanation for the lack of significant findings in these previous studies. The fact that the current study was able to report significant changes could be due to the use of a more objective method (i.e. pedometers) to assess changes in physical activity levels. The increase in physical activity levels observed for the intervention participants in the present study could be of great clinical importance; it is well documented that walking for $\sim 30 \mathrm{~min} / \mathrm{d}$ on $5 \mathrm{~d}$ /week is associated with a $19 \%$ reduction in CHD risk $^{(33)}$.

Overall, the favourable dietary and physical activity changes recorded for the intervention groups in the present study are probably indicative of the effectiveness of the 'nutrition and lifestyle counselling' component of the programme in increasing the self-efficacy of the intervention participants to comply with the given health behaviour instructions. Adequate compliance of both intervention 
Table 3 Changes in the consumption of certain food groups, physical activity levels and BMI during the 3-month intervention period according to study group: hypercholesterolaemic adults ( $n$ 101) aged $40-60$ years, Athens, Greece

\begin{tabular}{|c|c|c|c|c|c|c|c|}
\hline & \multicolumn{2}{|c|}{ Baseline } & \multicolumn{2}{|c|}{ 3-month follow-up } & \multicolumn{2}{|c|}{ 3-month change } & \multirow[b]{2}{*}{$P$ value $^{\star}$} \\
\hline & Mean & SD & Mean & SD & Mean & $95 \% \mathrm{Cl}$ & \\
\hline Total fisht & & & & & & & 0.340 \\
\hline CG & $0 \cdot 71$ & $1 \cdot 42$ & $0 \cdot 31$ & $0 \cdot 60$ & $-0 \cdot 38$ & $-1 \cdot 04,0 \cdot 28$ & \\
\hline PMG & 0.55 & $1 \cdot 46$ & 0.74 & $1 \cdot 64$ & $0 \cdot 19$ & $-0.35,0.73$ & \\
\hline EMG & 0.42 & $0 \cdot 81$ & $0 \cdot 74$ & 0.96 & $0 \cdot 31$ & $-0.20,0.82$ & \\
\hline$P$ value $\ddagger$ & \multicolumn{2}{|c|}{0.503} & \multicolumn{2}{|c|}{$0 \cdot 290$} & & & \\
\hline Fatty fisht & & & & & & & 0.678 \\
\hline CG & 0.51 & $1 \cdot 38$ & 0.23 & 0.56 & -0.26 & $-0 \cdot 83,0 \cdot 31$ & \\
\hline PMG & 0.55 & $1 \cdot 46$ & $0 \cdot 60$ & $1 \cdot 33$ & 0.05 & $-0.42,0.51$ & \\
\hline EMG & $0 \cdot 21$ & 0.48 & 0.35 & $0 \cdot 76$ & $0 \cdot 14$ & $-0.30,0.58$ & \\
\hline$P$ value $\ddagger$ & \multicolumn{2}{|c|}{0.973} & \multicolumn{2}{|c|}{0.562} & & & \\
\hline Whole grainst & & & & & & & 0.025 \\
\hline CG & $1 \cdot 29$ & $2 \cdot 37$ & $0 \cdot 79$ & $1 \cdot 07$ & $-0.68^{a}$ & $-1 \cdot 39,0.04$ & \\
\hline PMG & $0 \cdot 81$ & $2 \cdot 01$ & $0.59^{b}$ & $0 \cdot 87$ & -0.17 & $-0.75,0.41$ & \\
\hline EMG & $0 \cdot 71$ & $1 \cdot 35$ & $1 \cdot 37^{\mathrm{b}}$ & $1 \cdot 44$ & $0.73^{a}$ & $0 \cdot 17,1 \cdot 29$ & \\
\hline$P$ value $\ddagger$ & \multicolumn{2}{|c|}{0.961} & \multicolumn{2}{|c|}{0.026} & & & \\
\hline Fruitst & & & & & & & $0 \cdot 124$ \\
\hline CG & $1 \cdot 45$ & $1 \cdot 82$ & $1 \cdot 32$ & $1 \cdot 24$ & $-0 \cdot 18$ & $-1 \cdot 08,0 \cdot 71$ & \\
\hline PMG & 1.99 & $1 \cdot 73$ & $1 \cdot 85$ & $2 \cdot 11$ & $-0 \cdot 12$ & $-0.85,0.61$ & \\
\hline EMG & $1 \cdot 80$ & $2 \cdot 19$ & $2 \cdot 37$ & $2 \cdot 60$ & 0.59 & $-0 \cdot 10,1 \cdot 28$ & \\
\hline$P$ value $\ddagger$ & \multicolumn{2}{|c|}{0.232} & \multicolumn{2}{|c|}{0.359} & & & \\
\hline Vegetables & & & & & & & 0.677 \\
\hline CG & $1 \cdot 39$ & 1.05 & $2 \cdot 27$ & $1 \cdot 47$ & $0 \cdot 71$ & $-0.21,1.63$ & \\
\hline PMG & $2 \cdot 01$ & $1 \cdot 62$ & $2 \cdot 77$ & $2 \cdot 06$ & $0 \cdot 81$ & $0.06,1.55$ & \\
\hline EMG & $2 \cdot 09$ & $1 \cdot 25$ & $3 \cdot 24$ & $2 \cdot 19$ & $1 \cdot 19$ & $0 \cdot 48,1 \cdot 89$ & \\
\hline$P$ value $\ddagger$ & \multicolumn{2}{|c|}{0.298} & \multicolumn{2}{|c|}{$0 \cdot 181$} & & & \\
\hline Cheese & & & & & & & 0.096 \\
\hline CG & $1 \cdot 34$ & $1 \cdot 01$ & $1 \cdot 60$ & $1 \cdot 50$ & $0 \cdot 18$ & $-0.45,0.81$ & \\
\hline PMG & $1 \cdot 75$ & $1 \cdot 37$ & $1 \cdot 02$ & $0 \cdot 79$ & $-0 \cdot 71$ & $-1 \cdot 22,-0 \cdot 20$ & \\
\hline EMG & $1 \cdot 64$ & $1 \cdot 41$ & $1 \cdot 09$ & $0 \cdot 86$ & -0.52 & $-1.01,-0.03$ & \\
\hline$P$ value $\ddagger$ & \multicolumn{2}{|c|}{0.678} & \multicolumn{2}{|c|}{0.096} & & & \\
\hline Milk & & & & & & & $<0.001$ \\
\hline CG & 0.40 & 0.62 & $0.45^{\mathrm{a}, \mathrm{c}}$ & 0.58 & $-0.04^{a, c}$ & $-0.44,0.36$ & \\
\hline PMG & 0.51 & 0.97 & $1 \cdot 24^{\mathrm{C}}$ & 0.60 & $0 \cdot 76^{\mathrm{c}}$ & $0.43,1.08$ & \\
\hline EMG & 0.45 & 0.49 & $1 \cdot 48^{a}$ & $1 \cdot 06$ & $1 \cdot 06^{a}$ & $0 \cdot 75,1 \cdot 37$ & \\
\hline$P$ value $\neq$ & \multicolumn{2}{|c|}{0.894} & \multicolumn{2}{|c|}{0.000} & & & \\
\hline Meatt & & & & & & & 0.292 \\
\hline CG & $2 \cdot 16$ & $1 \cdot 71$ & $1 \cdot 18$ & $1 \cdot 04$ & -0.90 & $-2 \cdot 09,0 \cdot 29$ & \\
\hline PMG & $2 \cdot 67$ & $1 \cdot 88$ & $2 \cdot 75$ & $3 \cdot 10$ & $0 \cdot 60$ & $-0.90,1.02$ & \\
\hline EMG & $1 \cdot 61$ & $1 \cdot 62$ & $1 \cdot 90$ & $2 \cdot 16$ & $0 \cdot 26$ & $-0 \cdot 67,1 \cdot 18$ & \\
\hline$P$ value $\ddagger$ & \multicolumn{2}{|c|}{0.032} & & & & & \\
\hline Steps/d & & & & & & & 0.029 \\
\hline CG & 8705 & 3133 & 7716 & 3005 & $-1326^{c}$ & $-3026,374$ & \\
\hline PMG & 8029 & 3090 & 9633 & 3219 & $1633^{\mathrm{C}}$ & 268, 2998 & \\
\hline EMG & 7446 & 3483 & 8231 & 2744 & 958 & $-327,2244$ & \\
\hline$P$ value $\ddagger$ & & & & & & & \\
\hline BMI $\left(\mathrm{kg} / \mathrm{m}^{2}\right)$ & & & & & & & $0 \cdot 017$ \\
\hline $\mathrm{CG}$ & $27 \cdot 0$ & $3 \cdot 6$ & $26 \cdot 8$ & $3 \cdot 8$ & $-0 \cdot 2$ & $-0 \cdot 4,0 \cdot 2$ & \\
\hline PMG & $28 \cdot 6$ & $4 \cdot 3$ & $27 \cdot 8$ & $4 \cdot 3$ & -0.7 & $-0.9,-0.5$ & \\
\hline EMG & $28 \cdot 4$ & $3 \cdot 4$ & $27 \cdot 9$ & $3 \cdot 3$ & -0.5 & $-0.8,-0.3$ & \\
\hline$P$ value $\neq$ & & & & & & & \\
\hline
\end{tabular}

EMG, enriched milk group ( $n$ 40); PMG, placebo milk group ( $n$ 36); CG, control group ( $n$ 25).

All analyses were controlled for educational status.

Mean values were significantly different $(P<0 \cdot 05):{ }^{a} E M G$ v. CG; ${ }^{b} E M G$ v. PMG; ${ }^{~} P M G ~ v$. CG.

${ }^{*}$ Treatment $\times$ time interaction effect.

tValues were rank transformed.

‡Between-group comparisons at baseline and 3 months (treatment effect).

groups to the holistic intervention scheme provided to them could support the more favourable BMI changes observed in the EMG and PMG compared with the CG $\left(-0.5,-0.7 v .-0.2 \mathrm{~kg} / \mathrm{m}^{2}\right.$ respectively, $\left.P=0 \cdot 017\right)$. A significant BMI reduction by $0.7 \mathrm{~kg} / \mathrm{m}^{2}$ was also observed in another study that focused on reducing CVD risk factors via the implementation of healthy lifestyle counselling sessions for a period of 12 months $^{(34)}$, which is longer than the 3-month duration of the current intervention.

The effect of the increased PUFA intake in the intervention groups, which was probably and mainly through the increased consumption of fatty fish, although not significant compared with the CG, could be reflected in the respective significant increases in the EPA content of 
Table 4 Changes in the concentrations of selected fatty acids in erythrocyte membranes and plasma vitamin $\mathrm{B}_{12}$ and folic acid levels during the 3-month intervention period according to study group: hypercholesterolaemic adults ( $n$ 101) aged $40-60$ years, Athens, Greece

\begin{tabular}{|c|c|c|c|c|c|c|c|}
\hline & \multicolumn{2}{|c|}{ Baseline } & \multicolumn{2}{|c|}{ 3-month follow-up } & \multicolumn{2}{|c|}{ 3-month change } & \multirow[b]{2}{*}{$P$ value* } \\
\hline & Mean & SD & Mean & SD & Mean & $95 \% \mathrm{Cl}$ & \\
\hline Linoleic acid $(18: 2 n-6)(\mu \mathrm{g} / \mathrm{g})$ & & & & & & & 0.678 \\
\hline CG & $8 \cdot 64$ & 0.69 & $8 \cdot 54$ & $0 \cdot 83$ & -0.09 & $-0 \cdot 35,0 \cdot 17$ & \\
\hline PMG & $8 \cdot 76$ & $1 \cdot 00$ & $8 \cdot 80$ & $1 \cdot 16$ & 0.04 & $-0 \cdot 17,0.25$ & \\
\hline EMG & $8 \cdot 78$ & $1 \cdot 05$ & $8 \cdot 84$ & $1 \cdot 06$ & 0.05 & $-0 \cdot 15,0 \cdot 25$ & \\
\hline$P$ valuet & \multicolumn{2}{|c|}{0.887} & \multicolumn{2}{|c|}{0.617} & & & \\
\hline$\alpha$-Linolenic acid $(19: 3 n-3)(\mu \mathrm{g} / \mathrm{g})$ & & & & & & & 0.524 \\
\hline CG & 0.097 & 0.024 & 0.086 & 0.015 & -0.009 & $-0.020,0.002$ & \\
\hline PMG & 0.089 & 0.027 & 0.085 & 0.015 & -0.004 & $-0.013,0.005$ & \\
\hline EMG & 0.087 & 0.020 & 0.087 & 0.020 & -0.001 & $-0.009,0.008$ & \\
\hline$P$ valuet & \multicolumn{2}{|c|}{0.365} & \multicolumn{2}{|c|}{0.844} & & & \\
\hline Arachidonic acid $(20: 4 n-6)(\mu \mathrm{g} / \mathrm{g})$ & & & & & & & 0.486 \\
\hline CG & $14 \cdot 1$ & $1 \cdot 2$ & $14 \cdot 4$ & $1 \cdot 2$ & $0 \cdot 21$ & $-0 \cdot 12,0.54$ & \\
\hline PMG & $14 \cdot 1$ & $1 \cdot 3$ & $14 \cdot 1$ & $1 \cdot 1$ & -0.02 & $-0.28,0.25$ & \\
\hline EMG & $14 \cdot 1$ & $1 \cdot 1$ & $14 \cdot 1$ & $1 \cdot 1$ & -0.02 & $-0.28,0.23$ & \\
\hline$P$ valuet & \multicolumn{2}{|c|}{0.986} & \multicolumn{2}{|c|}{$0 \cdot 441$} & & & \\
\hline EPA $(20: 5 n-3)(\mu \mathrm{g} / \mathrm{g})$ & & & & & & & 0.001 \\
\hline CG & 0.59 & $0 \cdot 31$ & 0.57 & 0.23 & $-0 \cdot 03^{a, c}$ & $-0 \cdot 10,0.04$ & \\
\hline PMG & 0.54 & $0 \cdot 19$ & $0 \cdot 68$ & $0 \cdot 25$ & $0 \cdot 15^{\mathrm{c}}$ & $0 \cdot 09,0 \cdot 21$ & \\
\hline EMG & 0.55 & $0 \cdot 18$ & 0.64 & $0 \cdot 21$ & $0.09^{a}$ & $0 \cdot 04,0 \cdot 15$ & \\
\hline$P$ valuet & \multicolumn{2}{|c|}{0.604} & \multicolumn{2}{|c|}{0.169} & & & \\
\hline DHA $(22: 6 n-3)(\mu \mathrm{g} / \mathrm{g})$ & & & & & & & $0 \cdot 181$ \\
\hline CG & 4.98 & 0.98 & $5 \cdot 57$ & $0 \cdot 88$ & 0.64 & $0.32,0.95$ & \\
\hline PMG & $4 \cdot 98$ & $1 \cdot 22$ & $6 \cdot 01$ & $1 \cdot 33$ & $1 \cdot 02$ & $0 \cdot 76,1 \cdot 27$ & \\
\hline EMG & $5 \cdot 30$ & 0.92 & $6 \cdot 22$ & $1 \cdot 01$ & 0.91 & $0 \cdot 66,1 \cdot 15$ & \\
\hline$P$ valuet & \multicolumn{2}{|c|}{0.415} & \multicolumn{2}{|c|}{0.201} & & & \\
\hline Total $n$-3 PUFA $(\mu \mathrm{g} / \mathrm{g})$ & & & & & & & 0.063 \\
\hline CG & $7 \cdot 98$ & $1 \cdot 34$ & $8 \cdot 58$ & $1 \cdot 18$ & 0.64 & $0 \cdot 26,1 \cdot 03$ & \\
\hline PMG & $7 \cdot 96$ & $1 \cdot 49$ & $9 \cdot 22$ & $1 \cdot 62$ & $1 \cdot 25$ & $0.93,1.56$ & \\
\hline EMG & $8 \cdot 24$ & $1 \cdot 14$ & $9 \cdot 30$ & $1 \cdot 20$ & $1 \cdot 05$ & $0.75,1.35$ & \\
\hline$P$ valuet & \multicolumn{2}{|c|}{0.671} & \multicolumn{2}{|c|}{0.212} & & & \\
\hline$n-3: n-6$ & & & & & & & 0.368 \\
\hline CG & $3 \cdot 70$ & $0 \cdot 76$ & $3 \cdot 43$ & 0.63 & -0.30 & $-0.51,-0.09$ & \\
\hline PMG & $3 \cdot 75$ & 0.86 & $3 \cdot 24$ & $0 \cdot 82$ & -0.50 & $-0.67,-0.33$ & \\
\hline EMG & $3 \cdot 54$ & $0 \cdot 71$ & $3 \cdot 12$ & 0.58 & -0.41 & $-0.58,-0.25$ & \\
\hline$P$ valuet & \multicolumn{2}{|c|}{0.588} & \multicolumn{2}{|c|}{0.382} & & & \\
\hline AA:EPA & & & & & & & 0.222 \\
\hline CG & $27 \cdot 4$ & $9 \cdot 9$ & $27 \cdot 8$ & $8 \cdot 6$ & 0.22 & $-6 \cdot 34,6 \cdot 79$ & \\
\hline PMG & $30 \cdot 1$ & $12 \cdot 2$ & $23 \cdot 7$ & $9 \cdot 9$ & $-6 \cdot 37$ & $-11 \cdot 7,-1 \cdot 03$ & \\
\hline EMG & $31 \cdot 1$ & $22 \cdot 8$ & $24 \cdot 4$ & 8.9 & $-6 \cdot 61$ & $-11 \cdot 7,-1 \cdot 53$ & \\
\hline$P$ valuet & \multicolumn{2}{|c|}{0.670} & & & & & \\
\hline Vitamin $B_{12}(p g / m l)$ & & & & & & & $<0.001$ \\
\hline CG & 416 & 150 & $381^{a}$ & 123 & $-36^{a}$ & $-69,-4$ & \\
\hline PMG & 459 & 127 & 446 & 123 & $-13^{b}$ & $-40,14$ & \\
\hline EMG & 390 & 100 & $490^{\mathrm{a}}$ & 151 & $101^{a, b}$ & 76,126 & \\
\hline$P$ valuet & & & & & & & \\
\hline Folic acid (ng/ml) & & & & & & & $<0.001$ \\
\hline CG & $8 \cdot 4$ & $3 \cdot 7$ & $9 \cdot 2^{\mathrm{a}}$ & $4 \cdot 5$ & $0.9^{a}$ & $-0 \cdot 4,2 \cdot 2$ & \\
\hline PMG & $8 \cdot 0$ & $2 \cdot 9$ & $9 \cdot 5^{\mathrm{b}}$ & $2 \cdot 9$ & $1 \cdot 5^{\mathrm{b}}$ & $0.4,2.5$ & \\
\hline EMG & $8 \cdot 4$ & $3 \cdot 3$ & $14 \cdot 5^{\mathrm{a}, \mathrm{b}}$ & $4 \cdot 2$ & $6 \cdot 0^{\mathrm{a}, \mathrm{b}}$ & $5 \cdot 0,7 \cdot 0$ & \\
\hline$P$ valuet & & & & & & & \\
\hline
\end{tabular}

EMG, enriched milk group ( $n$ 40); PMG, placebo milk group ( $n$ 36); CG, control group ( $n$ 25).

All analyses were controlled for educational status.

Mean values were significantly different $(P<0 \cdot 05)$ : ${ }^{a}$ EMG $v$. CG; ${ }^{b}$ EMG $v$. PMG; ${ }^{c} P M G v$. CG.

*Treatment $\times$ time interaction effect.

tBetween-group comparisons at baseline and 3 months (treatment effect).

erythrocyte membranes. Still, no other significant differences were observed among study groups regarding the erythrocyte membrane contents of linoleic acid and $\alpha$-linolenic acid, although the EMG was provided with an additional amount of $0 \cdot 2 \mathrm{~g}$ of linolenic acid and $2 \cdot 15 \mathrm{~g}$ of linoleic acid daily $(\sim 20 \%$ of the recommended Adequate Intakes, respectively) ${ }^{(35)}$. Probably the amounts of these two essential PUFA provided by the fortified milk to the EMG were not sufficient to induce significant changes in the concentration of these two fatty acids in erythrocyte membranes and this probably requires further intervention. Furthermore, it should be mentioned here that $\alpha$-linolenic acid is normally metabolically converted to more elongated and unsaturated fatty acids, the sequence ending in EPA and DHA. As a result, the amounts of $\alpha$-linolenic acid in plasma and erythrocyte membranes 
Table 5 Changes in certain CVD risk indices during the 3-month intervention period according to study group: hypercholesterolaemic adults ( $n$ 101) aged 40-60 years, Athens, Greece

\begin{tabular}{|c|c|c|c|c|c|c|c|}
\hline & \multicolumn{2}{|c|}{ Baseline } & \multicolumn{2}{|c|}{ 3-month follow-up } & \multicolumn{2}{|c|}{ 3-month change } & \multirow[b]{2}{*}{$P$ value* } \\
\hline & Mean & SD & Mean & SD & Mean & $95 \% \mathrm{Cl}$ & \\
\hline LDL-C:HDL-C & & & & & & & 0.066 \\
\hline CG & $3 \cdot 15$ & $1 \cdot 07$ & 3.01 & 0.94 & $-0 \cdot 14$ & $-0 \cdot 40,0 \cdot 11$ & \\
\hline PMG & 3.45 & $1 \cdot 12$ & $3 \cdot 43$ & $1 \cdot 15$ & -0.02 & $-0.23,0.18$ & \\
\hline EMG & $3 \cdot 32$ & $1 \cdot 31$ & $2 \cdot 99$ & $1 \cdot 03$ & $-0 \cdot 32$ & $-0.52,-0.13$ & \\
\hline$P$ valuet & \multicolumn{2}{|c|}{0.718} & \multicolumn{2}{|c|}{0.257} & & & \\
\hline $\mathrm{SBP}(\mathrm{mmHg})$ & & & & & & & $0 \cdot 898$ \\
\hline $\mathrm{CG}$ & $126 \cdot 0$ & $13 \cdot 8$ & $123 \cdot 3$ & $10 \cdot 0$ & $-2 \cdot 3$ & $-8 \cdot 9,4 \cdot 4$ & \\
\hline PMG & $130 \cdot 5$ & $25 \cdot 4$ & $122 \cdot 4$ & $11 \cdot 7$ & $-8 \cdot 3$ & $-13 \cdot 7,-2 \cdot 9$ & \\
\hline EMG & $132 \cdot 0$ & $16 \cdot 9$ & $127 \cdot 2$ & $18 \cdot 0$ & $-4 \cdot 9$ & $-10 \cdot 0,-0 \cdot 1$ & \\
\hline$P$ valuet & \multicolumn{2}{|c|}{0.639} & \multicolumn{2}{|c|}{$0 \cdot 398$} & & & \\
\hline $\mathrm{DBP}(\mathrm{mmHg}) \ddagger$ & & & & & & & 0.396 \\
\hline CG & $79 \cdot 4$ & $8 \cdot 4$ & $77 \cdot 7$ & $7 \cdot 0$ & $-1 \cdot 8$ & $-7 \cdot 8,4 \cdot 3$ & \\
\hline PMG & $83 \cdot 2$ & $10 \cdot 8$ & $77 \cdot 6$ & $13 \cdot 9$ & $-5 \cdot 5$ & $-10 \cdot 4,-0 \cdot 6$ & \\
\hline EMG & $83 \cdot 5$ & $11 \cdot 6$ & $81 \cdot 9$ & $10 \cdot 4$ & $-1 \cdot 5$ & $-6 \cdot 2,3 \cdot 1$ & \\
\hline$P$ valuet & \multicolumn{2}{|c|}{0.427} & \multicolumn{2}{|c|}{0.312} & & & \\
\hline CRP $(\mathrm{mg} / \mathrm{dl}) \ddagger$ & & & & & & & 0.003 \\
\hline CG & $2 \cdot 60$ & $3 \cdot 25$ & $2 \cdot 83$ & $2 \cdot 35$ & $0 \cdot 43^{a, c}$ & $-0 \cdot 60,1 \cdot 46$ & \\
\hline PMG & $2 \cdot 93$ & $2 \cdot 28$ & $2 \cdot 14$ & 1.95 & $-0 \cdot 86^{c}$ & $-1 \cdot 70,-0.02$ & \\
\hline EMG & $2 \cdot 94$ & $2 \cdot 46$ & $2 \cdot 07$ & $1 \cdot 43$ & $-0.94^{\mathrm{a}}$ & $-0.74,-0.14$ & \\
\hline$P$ valuet & \multicolumn{2}{|c|}{0.118} & \multicolumn{2}{|c|}{0.411} & & & \\
\hline Homocysteine $(\mu \mathrm{mo} / \mathrm{l}) \ddagger$ & & & & & & & $<0.001$ \\
\hline CG & $11 \cdot 6$ & $3 \cdot 4$ & $12 \cdot 1^{\mathrm{a}}$ & $3 \cdot 3$ & $0 \cdot 5^{\mathrm{a}}$ & $-0 \cdot 6,1 \cdot 5$ & \\
\hline PMG & $12 \cdot 2$ & $3 \cdot 0$ & $11 \cdot 8$ & $2 \cdot 6$ & $-0 \cdot 3^{b}$ & $-1 \cdot 2,0 \cdot 5$ & \\
\hline EMG & $13 \cdot 4$ & $4 \cdot 5$ & $10 \cdot 4^{a}$ & $2 \cdot 1$ & $-3 \cdot 0^{a, b}$ & $-3 \cdot 8,-2 \cdot 1$ & \\
\hline$P$ valuet & \multicolumn{2}{|c|}{0.121} & \multicolumn{2}{|c|}{0.019} & & & \\
\hline
\end{tabular}

LDL-C, LDL cholesterol; HDL-C, HDL cholesterol; EMG, enriched milk group ( $n$ 40); PMG, placebo milk group ( $n$ 36); CG, control group ( $n$ 25); SBP, systolic blood pressure; DBP, diastolic blood pressure; CRP, C-reactive protein.

All analyses were controlled for educational status.

Mean values were significantly different $(P<0 \cdot 05)$ : ${ }^{a}$ EMG v. CG; ${ }^{b} E M G$ v. PMG; ${ }^{c} P M G$ v. CG.

*Treatment $\times$ time interaction effect.

tBetween-group comparisons at baseline and 3 months (treatment effect).

$\ddagger$ Values were rank transformed.

are expected to be low. In the human body the conversion yield of $\alpha$-linolenic acid into EPA is relatively low - about 5-6\% - while the conversion to DHA is almost negligible $^{(36)}$. Hence, EPA in erythrocyte membranes might originate from dietary sources - i.e. fish and seafood and probably to a lesser extent from metabolic conversion of dietary $\alpha$-linolenic acid. This fact could provide another explanation for the lack of a significant increase in $\alpha$-linolenic acid in EMG participants (originating from the $\alpha$-linolenic intake from milk) and further explain the significant increment of EPA in erythrocyte membranes of both intervention groups (originating from changes in diet). This is another finding of the present study with potential clinical importance and application regarding CVD risk reduction.

Overall, the more favourable dietary, physical activity and BMI changes induced in the EMG and PMG may have also contributed to the significant decrease in CRP and blood pressure levels in these two groups compared with the CG. Regarding the effect of dietary factors on inflammation, $n-3$ fatty acids have well-established antiinflammatory properties ${ }^{(37)}$. Furthermore, the intake of fish and fish oils has been reported to exert a beneficial effect on certain CVD risk factors, such as on circulating levels of inflammatory markers ${ }^{(38)}$, and thus on the prevention of chronic diseases involving inflammatory processes ${ }^{(5)}$. Regarding the effect of BMI changes on CRP levels, previous studies have reported that obesity represents a low-grade chronic inflammatory state that is positively associated with increased CRP levels ${ }^{(39,40)}$. In this context, lifestyle intervention studies that favour changes in diet and exercise habits and have proved sufficient in achieving modest weight loss can also improve plasma levels of inflammatory cytokines such as CRP, IL-6 and TNF- $\alpha^{(41)}$. The clinical importance of the decrease in CRP levels reported for the intervention participants in the present study is further supported by a meta-analysis of twenty-two prospective studies, showing that patients with high plasma levels of CRP had a $45 \%$ increase in CHD events compared with those with lower CRP levels ${ }^{(42)}$.

Moreover, significant within-group decreases in systolic blood pressure were observed in the EMG and PMG (4.9 and $8.3 \mathrm{mmHg}$, respectively). Epidemiological studies have shown that for every $10 \mathrm{mmHg}$ reduction in systolic blood pressure, there is a $33 \%$ decline in the risk of stroke ${ }^{(43)}$. The increase in milk consumption in both the EMG and PMG could partly explain these favourable changes observed in systolic blood pressure. Based on growing evidence over the last years, regular consumption of dairy products is actively involved in blood 
pressure regulation ${ }^{(19,44)}$. The blood-pressure-lowering effect of dairy products has been reported to be mainly attributed to their high content of specific nutrients, namely $\mathrm{Ca}, \mathrm{K}$ and $\mathrm{Mg}^{(19)}$.

All of the favourable changes reported above for both the EMG and PMG could be mainly ascribed to the combined lifestyle counselling and the consumption of plain milk. The additional positive effect of nutrients that were used in the fortification of milk consumed by participants in the EMG could be mainly reflected in the significant within-group decreases observed in LDLC:HDL-C and homocysteine levels. Regarding changes in serum lipids, it is well known that in the context of a healthier lifestyle, the consumption of products enriched with plant sterols/stanols can reduce LDL-C levels by $10-14 \%^{(45)}$. This was also confirmed by the findings of the present study which showed a $12.6 \%$ mean reduction in LDL-C levels as reported elsewhere ${ }^{(46)}$. Another possible explanation for the decrease in LDL-C:HDL-C in the EMG could probably stem from the increase in the consumption of whole grains observed for this group over the intervention period. A recent meta-analysis showed that greater whole grains consumption $(2.5$ servings/d $v$. $0 \cdot 2$ servings/d) was associated with a $21 \%$ lower risk of CVD events ${ }^{(47)}$.

Regarding the significant decrease in homocysteine levels observed for the EMG, this could be attributed to the fortification of milk with folic acid and vitamin $B_{12}$. Higher intake of these nutrients by the EMG resulted in increased plasma levels, hence leading to the favourable reductions in plasma homocysteine levels in this group. As homocysteine is an independent risk factor for CVD, a reduction in its plasma levels is related to a decrease in relevant mortality and morbidity ${ }^{(14,48)}$.

The current study has certain strengths and limitations. Regarding strengths, to our knowledge the present study is the first intervention with enriched food products estimating changes of $n-3$ and $n-6$ PUFA levels in erythrocyte membranes rather than in plasma; although the former is highly modifiable, the latter is still the most common approach to assess nutritional status of PUFA. Regarding limitations, the quantities of nutrients used to enrich milk were in some cases not adequate to induce statistically significant changes to certain biochemical indices of their dietary intake. This is probably most obvious in the case of $\alpha$-linolenic acid, in which the supplemented dose of $0.04 \mathrm{~g} / 100 \mathrm{ml}$ was possibly not adequate to significantly improve its content in erythrocyte membranes. Furthermore, although an extra group that would only receive placebo milk but without attending sessions would be useful to assess the real benefits of the educational component of intervention, still the main focus of the current study was to examine holistically the combined effect of a functional food with lifestyle counselling on behavioural and clinical risk indices of CVD.

\section{Conclusions}

The results of the present study revealed favourable changes in dietary and physical activity indices in both intervention groups that attended the lifestyle counselling sessions. These favourable lifestyle changes probably resulted in reductions in blood pressure and CRP levels in the EMG and PMG. An additional benefit of combining counselling with fortified milk was observed in the EMG, mainly in terms of decreases in LDL-C:HDL-C and homocysteine levels. Although the fortification of milk with only $0.04 \mathrm{~g} \alpha$-linolenic $/ 100 \mathrm{ml}$ in the current study seems not to have been sufficient to exert additional benefits in the EMG in terms of erythrocyte membrane PUFA content and blood pressure levels, the supplemented amounts of phytosterols, vitamin $\mathrm{B}_{12}$ and folic acid were found to be sufficient to induce favourable changes in LDL-C:HDL-C and homocysteine levels in this group. Further research is probably needed to address the issue of optimal fortification of milk or other food products and their effect on CVD, especially when combined with lifestyle counselling.

\section{Acknowledgements}

Sources of funding: The present study was supported by a research grant from Friesland Campina Hellas. Conflicts of interest: Y.M. works as a part-time scientific consultant for Friesland Campina Hellas. M.P., E.G., N.K., A.P., G.M., C.P. and S.A. have no potential conflicts of interest. Authors' contributions: M.P. and Y.M. contributed in the conception and design of the study. All authors contributed to data analysis and interpretation, drafting the article and approving the final version submitted. Acknowledgements: The authors would like to thank Dionysia Argyropoulou and Kostalenia Kallianioti for their help throughout the study.

\section{References}

1. American Heart Association (2009) International Cardiovascular Disease Statistics - Statistical Fact Sheet Populations. Dallas, TX: AHA.

2. Katan MB, Grundy SM, Jones P et al. (2003) Efficacy and safety of plant stanols and sterols in the management of blood cholesterol levels. Mayo Clin Proc 78, 965-978.

3. Connor WE (2000) Importance of $n-3$ fatty acids in health and disease. Am J Clin Nutr 71, 1 Suppl., 171S-175S.

4. von Schacky C (2000) $n$-3 fatty acids and the prevention of coronary atherosclerosis. Am J Clin Nutr 71, 1 Suppl., 224S-227S.

5. Wall R, Ross RP, Fitzgerald GF et al. (2010) Fatty acids from fish: the anti-inflammatory potential of long-chain omega-3 fatty acids. Nutr Rev 68, 280-289.

6. Carrero JJ, Baro L, Fonolla J et al. (2004) Cardiovascular effects of milk enriched with omega-3 polyunsaturated fatty acids, oleic acid, folic acid, and vitamins $\mathrm{E}$ and $\mathrm{B}_{6}$ in volunteers with mild hyperlipidemia. Nutrition 20, 521-527.

7. Miles EA, Thies F, Wallace FA et al. (2001) Influence of age and dietary fish oil on plasma soluble adhesion molecule concentrations. Clin Sci (Lond) 100, 91-100. 
8. Esterbauer H, Waeg G, Puhl H et al. (1992) Inhibition of LDL oxidation by antioxidants. EXS 62, 145-157.

9. Niki E (1987) Interaction of ascorbate and $\alpha$-tocopherol. Ann N Y Acad Sci 498, 186-199.

10. Reaven PD, Khouw A, Beltz WF et al. (1993) Effect of dietary antioxidant combinations in humans. Protection of LDL by vitamin E but not by $\beta$-carotene. Arterioscler Thromb 13, 590-600.

11. Steinberg D (1995) Clinical trials of antioxidants in atherosclerosis: are we doing the right thing? Lancet $\mathbf{3 4 6}$, 36-38.

12. McKinley MC, McNulty H, McPartlin J et al. (2001) Lowdose vitamin B-6 effectively lowers fasting plasma homocysteine in healthy elderly persons who are folate and riboflavin replete. Am J Clin Nutr 73, 759-764.

13. Rimm EB, Willett WC, Hu FB et al. (1998) Folate and vitamin $\mathrm{B}_{6}$ from diet and supplements in relation to risk of coronary heart disease among women. JAMA 279, 359-364.

14. Refsum H, Ueland PM, Nygard O et al. (1998) Homocysteine and cardiovascular disease. Annu Rev Med 49, 31-62.

15. Siri PW, Verhoef P \& Kok FJ (1998) Vitamins $B_{6}, B_{12}$, and folate: association with plasma total homocysteine and risk of coronary atherosclerosis. J Am Coll Nutr 17, 435-441.

16. Rees MM \& Rodgers GM (1993) Homocysteinemia: association of a metabolic disorder with vascular disease and thrombosis. Thromb Res 71, 337-359.

17. Kawano Y, Matsuoka H, Takishita S et al. (1998) Effects of magnesium supplementation in hypertensive patients: assessment by office, home, and ambulatory blood pressures. Hypertension 32, 260-265.

18. Kawano Y, Yoshimi H, Matsuoka H et al. (1998) Calcium supplementation in patients with essential hypertension: assessment by office, home and ambulatory blood pressure. J Hypertens 16, 1693-1699.

19. McGrane MM, Essery E, Obbagy J et al. (2011) Dairy consumption, blood pressure, and risk of hypertension: an evidence-based review of recent literature. Curr Cardiovasc Risk Rep 5, 287-298.

20. Abood DA, Black DR \& Feral D (2003) Nutrition education worksite intervention for university staff: application of the health belief model. J Nutr Educ Behav 35, 260-267.

21. Prochaska JO \& Velicer WF (1997) The transtheoretical model of health behavior change. Am J Health Promot 12, 38-48.

22. El Assaad MA, Topouchian JA \& Asmar RG (2003) Evaluation of two devices for self-measurement of blood pressure according to the international protocol: the Omron M5-I and the Omron 705IT. Blood Press Monit 8, 127-133.

23. University of Crete (1991) Food Composition Tables. http:// nutrition.med.uoc.gr/GreekTables (accessed November 2009).

24. Trichopoulou A (2001) Mediterranean diet: the past and the present. Nutr Metab Cardiovasc Dis 11, 1-4.

25. Strycker LA, Duncan SC, Chaumeton NR et al. (2007) Reliability of pedometer data in samples of youth and older women. Int J Behav Nutr Phys Act 4, 4.

26. Rose HG \& Oklander M (1965) Improved procedure for the extraction of lipids from human erythrocytes. J Lipid Res $\mathbf{6}$, 428-431.

27. Lepage G \& Roy CC (1986) Direct transesterification of all classes of lipids in a one-step reaction. J Lipid Res 27, 114-120.

28. Iacono JM (1987) Dietary intervention studies to reduce risk factors related to cardiovascular diseases and cancer. Prev Med 16, 516-524.

29. Bemelmans WJ, Broer J, Feskens EJ et al. (2002) Effect of an increased intake of $\alpha$-linolenic acid and group nutritional education on cardiovascular risk factors: the Mediterranean Alpha-linolenic Enriched Groningen Dietary Intervention (MARGARIN) study. Am J Clin Nutr 75, 221-227.
30. Brownlee IA, Moore C, Chatfield M et al. (2010) Markers of cardiovascular risk are not changed by increased wholegrain intake: the WHOLEheart study, a randomised, controlled dietary intervention. Br J Nutr 104, 125-134.

31. Moschonis G, Katsaroli I, Lyritis GP et al. (2010) The effects of a 30-month dietary intervention on bone mineral density: the Postmenopausal Health Study. Br J Nutr 104, 100-107.

32. Wolff I, van Croonenborg JJ, Kemper HC et al. (1999) The effect of exercise training programs on bone mass: a meta-analysis of published controlled trials in pre- and postmenopausal women. Osteoporos Int 9, 1-12.

33. Zheng H, Orsini N, Amin J et al. (2009) Quantifying the dose-response of walking in reducing coronary heart disease risk: meta-analysis. Eur J Epidemiol 24, 181-192.

34. Nilsson PM, Klasson EB \& Nyberg P (2001) Life-style intervention at the worksite - reduction of cardiovascular risk factors in a randomized study. Scand J Work Environ Health 27, 57-62.

35. Institute of Medicine (2005) Dietary Reference Intakes for Energy, Carbohydrate, Fiber, Fat, Fatty Acids, Cholesterol, Protein, and Amino Acids. Washington, DC: National Academies Press.

36. Plourde M \& Cunnane SC (2007) Extremely limited synthesis of long chain polyunsaturates in adults: implications for their dietary essentiality and use as supplements. Appl Physiol Nutr Metab 32, 619-634.

37. Mori TA \& Beilin LJ (2004) Omega-3 fatty acids and inflammation. Curr Atheroscler Rep 6, 461-467.

38. Smith KM, Barraj LM, Kantor M et al. (2009) Relationship between fish intake, $n-3$ fatty acids, mercury and risk markers of CHD (National Health and Nutrition Examination Survey 1999-2002). Public Health Nutr 12, 1261-1269.

39. Matsushita K, Yatsuya H, Tamakoshi K et al. (2006) Comparison of circulating adiponectin and proinflammatory markers regarding their association with metabolic syndrome in Japanese men. Arterioscler Thromb Vasc Biol 26, 871-876.

40. Sell H \& Eckel J (2007) Monocyte chemotactic protein-1 and its role in insulin resistance. Curr Opin Lipidol 18, 258-262.

41. DeMarco VG, Johnson MS, Whaley-Connell AT et al. (2010) Cytokine abnormalities in the etiology of the cardiometabolic syndrome. Curr Hypertens Rep 12, 93-98.

42. Danesh J, Wheeler JG, Hirschfield GM et al. (2004) C-reactive protein and other circulating markers of inflammation in the prediction of coronary heart disease. $N$ Engl J Med 350, 1387-1397.

43. Lawes CM, Bennett DA, Feigin VL et al. (2004) Blood pressure and stroke: an overview of published reviews. Stroke 35, 1024.

44. Kris-Etherton PM, Grieger JA, Hilpert KF et al. (2009) Milk products, dietary patterns and blood pressure management. J Am Coll Nutr 28, Suppl. 1, 103S-119S.

45. Plat J \& Mensink RP (2005) Plant stanol and sterol esters in the control of blood cholesterol levels: mechanism and safety aspects. Am J Cardiol 96, 15D-22D.

46. Petrogianni M, Grammatikaki E, Pitsavos C et al. (2012) Changes in CVD risk factors after combined dietary counselling and supplementation with lipid-lowering milk product: the effect of compliance. e-SPEN J 7, e205-e210.

47. Mellen PB, Walsh TF \& Herrington DM (2008) Whole grain intake and cardiovascular disease: a meta-analysis. Nutr Metab Cardiovasc Dis 18, 283-290.

48. Reeder SJ, Hoffmann RL, Magdic KS et al. (2000) Homocysteine: the latest risk factor for heart disease. Dimens Crit Care Nurs 19, 22-28. 